\title{
Multiaxial Non-proportional Low Cycle Fatigue Properties of HIPped A319 Cast Aluminum Alloy
}

\author{
Bin $\mathrm{Ge}^{1}$, Xiaoshan $\mathrm{Liu}^{2}$, Guoqiu $\mathrm{He}^{2}$, Peiwen $\mathrm{Le}^{2}$, Zhiqiang Zhou ${ }^{1}$, Jiaqi Pan ${ }^{1}$, Ziao \\ Huang ${ }^{1}$, Jingquan $\mathrm{Li}^{1}$, and Qigui Wang ${ }^{3}$ \\ ${ }^{1}$ Affiliation not available \\ ${ }^{2}$ Tongji University \\ ${ }^{3}$ General Motors Corp
}

February 12, 2021

\begin{abstract}
This paper describes a microstructure-based multiaxial non-proportional fatigue life prediction model with maximum shear strain and non-proportionality as damage parameters applied to A319 alloy. The materials made with different casting cooling rates and $\mathrm{Sr}$ modification are characterized and quantified in terms of secondary dendrite arm spacing (SDAS), size and aspect ratio of eutectic Si particles. Multiaxial non-proportional fatigue tests have been performed on six groups of A319 alloys to systematically analyze the effect of microstructure and loading path on the fatigue properties of Al-Si cast alloy. The first part of the paper is focused on microstructure quantitative characterization to determine the influence of different casting conditions, followed by stress response behavior and fatigue fracture analysis. Finally, quantitative relationship between six fatigue life parameters and microstructure characteristics is established and a new fatigue life prediction model is proposed to predict fatigue life of Al-Si alloy under multiaxial non-proportional loading condition.
\end{abstract}

\section{Hosted file}

Multiaxial Non-proportional Low Cycle Fatigue Properties of HIPped A319 Cast Aluminum Alloy.pdf available at https://authorea.com/users/326248/articles/508594-multiaxial-non-proportionallow-cycle-fatigue-properties-of-hipped-a319-cast-aluminum-alloy

\section{Hosted file}

Multiaxial Non-proportional Low Cycle Fatigue Properties of HIPped A319 Cast Aluminum Alloy.pdf available at https://authorea.com/users/326248/articles/508594-multiaxial-non-proportionallow-cycle-fatigue-properties-of-hipped-a319-cast-aluminum-alloy

\section{Hosted file}

AUTHOR CONTRIBUTION STATEMENT.pdf available at https://authorea.com/users/326248/articles/ 508594-multiaxial-non-proportional-low-cycle-fatigue-properties-of-hipped-a319-castaluminum-alloy 